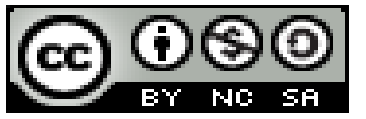

\title{
Grado de contaminación en los teléfonos celulares de docentes y estudiantes que realizan actividades en la clínica odontológica
}

Degree of contamination in the cell phones of teachers and students who carry out activities in the dental clinic

Grau de poluição nos telefones celulares de professores e estudantes que realizam atividades na clinica odontológica

Delia M. Villacrés-Yancha ${ }^{\mathrm{I}}$ dmvillac@yahoo.com

Myriam K. Zurita-Solís" kathy1zurita@hotmail.com

Recibido: 12 de diciembre de 2016 * Corregido: 16 de junio de 2016 * Aceptado: 21 de diciembre 2016

\footnotetext{
. I Odontóloga, Facultad de Odontología, Universidad Central del Ecuador, Quito, Ecuador.

. II Docente, Facultad de Odontología, Universidad Central del Ecuador, Quito, Ecuador.
} 


\section{Resumen.}

Objetivo: Determinar el grado de contaminación microbiana que poseen los teléfonos celulares de una muestra de docentes y estudiantes que laboran en la Clínica Integral de la Facultad de Odontología de la Universidad Central del Ecuador. Materiales y metodos: Se utilizo un estudio de tipo descriptivo, transversal, aplicando encuestas a 70 individuos para obtener información sobre los hábitos, actitudes y nivel de conocimientos sobre la contaminación microbiana de los teléfonos celulares; y se realizó un muestreo pre y pos desinfección de estos, para los cultivos consistentes en: Bacterias Aerobias Totales, E. Coli y Coliformes, Mohos y Levaduras. Los datos fueron analizados a través del paquete estadisco SPSS version 23, test estadístico ANOVA para el análisis cuantitativo y chi cuadrado para el análisis cualitativo. Resultados: Los resultados de la encuesta fueron que los participantes no tienen buenos hábitos y actitudes en la utilización de los teléfonos dentro del área clínica a pesar de que la mayoría si conocía de la contaminación de este, y los resultados microbiológicos mostraron cantidades altas de unidades formadoras de colonias de los microorganismos cultivados a excepción de E. Coli en un menor grado, y según la prueba de ANOVA existió una diferencia significativa $(\mathrm{p}<0,05)$ en el número medio de unidades formadoras de colonias para la etapa pre y pos desinfección. Conclusiones: Se determinó que el teléfono celular alberga varios microorganismos que tienen la posibilidad de producir infecciones cruzadas y que el grado de contaminación alto o bajo varía según como su dueño le manipule por lo que se debe aplicar una desinfección constante de este.

Palabras claves: Contaminantes; teléfonos celulares; infección cruzada; unidades formadoras de colonias; clinicas odontológicas. 

odontológica

\section{Abstract.}

Objective: Measure microbial contamination degree on teachers and students cell phones working at the Universidad Central del Ecuador School of Dentistry dental clinic. Equipment and Methods: After surveying 70 participants, a descriptive cross-sectional study was used to obtain information on habits, attitudes and knowledge about microbial contamination on cell phones. Pre and post disinfection samples were obtained for: Total Aerobic Bacteria, E. coli and Coliforms, Molds and Yeasts. Obtained data was analyzed with the SPSS version 23 statistical package using ANOVA statistical test for quantitative results and chi square analysis for the qualitative results. Results: Surveys indicate that despite the fact that most of the participants have knowledge about contamination, poor habits and attitudes towards telephone use are executed within the clinical area. Results showed high amounts of colony-forming units for bacteria's in study except for E. Coli. ANOVA test showed a significant difference $(\mathrm{P}<0.05)$ in colony-forming units between the pre and post-disinfection stage. Conclusions: Cellphones carry several microorganisms increasing chances of cross-infection. The contamination degree will vary depending on owner's manipulation; constant disinfection of cell phones is highly recommended.

Keywords: Contaminants; cell phone; cross-infection; colony-forming units; dental clinic. 


\section{Resumo.}

Objetivo: Avaliar o grau de contaminação microbiana que possuem os telefones celulares dos professores e estudantes que trabalham na Clínica Integral da Faculdade de Odontologia da Universidade Central do Equador. Materiais e Métodos: Estudo descritivo, de tipo transversal no qual se aplicou um questionário a 70 indivíduos para obter informação sobre os hábitos, atitudes e nível de conhecimento sobre a contaminação microbiana dos telefones celulares; amostras foram coletadas antes e após desinfecção dos aparelhos celulares, para cultura consistente em: Bactérias Aeróbias Totais, E. Coli e Coliformes, mofos e leveduras. Os dados foram analisados através do software estadístico SPSS versão 23, teste ANOVA para análise quantitativa e qui-quadrado para análise qualitativa foram realizados. Resultados: Os dados do questionário mostraram que os participantes não tinham bons hábitos e atitudes ao respeito do uso de telefones celulares na área clinica embora a maioria de eles sabia da poluição desta. Os resultados microbiológicos mostraram grandes quantidades de Unidades de Formação de Colônias (UFC) dos microrganismos avaliados excetuando E. Coli, que se apresentou num menor grau, e de acordo com o teste ANOVA, existiu diferença estatisticamente significativa $(\mathrm{p}<0,05)$ entre as meias das Unidades Formadoras de Colônias para as amostras antes e após desinfecção. Conclusões: Foi determinado que o telefone celular porta alguns microrganismos, os quais tem a possibilidade de produzir infecções cruzadas, e que o grau de poluição alto ou baixo depende de como o usuário manipula o aparelho celular, por tanto se sugere desinfecções constantes deste.

Palavras Chave: Poluentes; telefones celulares; unidades formadoras de colônias; clinicas odontológicas. 

odontológica

\section{Introducción.}

El teléfono celular es un dispositivo inalámbrico electrónico, que fue creado con fines de mejorar comunicación y su evolución a teléfonos celulares inteligentes con incontables funciones, gracias a los avances tecnológicos a través de varias décadas. (1)

Se han convertido en un instrumento inseparable de todas las personas, Sin embargo esta y otras tecnologías como cámaras fotográficas, computadores, presentes en la clínica permiten la transmisión de microorganismos patógenos a través de estos, capaces de difundir enfermedades graves. (2) En un estudio realizado en las manijas de las puertas, suela de zapato, el asiento de un baño, los teléfonos celulares entre otras se descubrió que había más suciedad en un teléfono celular que en los demás. (3)

Con los recientes avances en la fuente de información como las redes sociales, las aplicaciones, diversos juegos y la facilidad de comunicación que proporciona el teléfono celular; el uso constante de éste se ha vuelto indispensable para docentes y estudiantes que realizan procedimientos en Clínicas dentales; sin tomarse en cuenta su adecuada manipulación dejando pasar por alto la contaminación que éste posee.

Razón por la cual la presente investigación tiene como objetivo determinar el grado de contaminación que tienen los teléfonos celulares de una muestra de docentes y estudiantes que realizan actividades en la Clínica Integral, con el propósito de recomendar indicaciones de uso del teléfono celular durante los procedimientos odontológicos para prevenir posibles infecciones cruzadas, así como corregir las prácticas inadecuadas con respecto a su utilización; debido a que el 
Dom. Cien., ISSN: $2477-8818$

Vol. 3, núm. 1, enero, 2017, pp. 50-72

Grado de contaminación en los teléfonos celulares de docentes y estudiantes que realizan actividades en la clínica odontológica

teléfono celular es un objeto personal que no puede pasar desapercibido antes las normas de bioseguridad.

\section{Materiales y métodos.}

Se aplicaron encuestas a 70 individuos (estudiantes 23 de séptimo, 21 de octavo, 22 de noveno y 4 docentes) en la clínica integral de la facultad de Odontología de la Universidad Central del Ecuador, sobre los hábitos, actitudes y nivel de conocimiento sobre la contaminación microbiana de los teléfonos celulares; y a los mismos que se les solicitó la prestación de su teléfono celular para muestrearlo y realizar el análisis microbiano en medios de cultivos.

Se ingresó a la clínica y se solicitó al azar la participación de los estudiantes y docentes; después de explicar los beneficios de la investigación y una vez firmados los consentimientos informados se procedió a realizar las encuestas.

Se solicitó el teléfono celular, excluyendo aquellos cuya adquisición del teléfono fue menor a dos meses; el mismo que fue apagado por su dueño y depositado en una funda ziploc con el nombre de su dueño para su posterior devolución y usando guantes de látex.

Se realizó el muestreo dentro del área clínica, en donde se desinfectó la zona de trabajo con alcohol potable al $96 \%$ y se sacó el teléfono de la funda y colocándolo en un campo se realizó el hisopado con el hisopo Quick Swab de 3M, de las superficies frontal, lateral y posterior de los teléfonos celulares pre y pos desinfección de este con alcohol isopropílico.

Se preparó el hisopo Quick Swab para realizar el procedimiento de muestreo de superficie secas que es el teléfono celular, de la siguiente manera: se presionó el bulbo con el dedo pulgar 
hacia un lado para que la válvula se rompa y el caldo de cultivo letheen pase al tubo y moje el swab el mismo que es para el hisopado, se retira el swab del tubo y se pasó sobre las superficies del teléfono celular girándolo para atrapar los microorganismos presentes en este; se devolvió el swab al tubo y se almacenó para su posterior transporte al laboratorio de microbiología de la Facultad de Odontología de la UCE.

En el laboratorio se desinfectó el área de trabajo con alcohol potable al 96\%, y se procedió a realizar la dilución de la muestra, la cual contenía 1cc de caldo letheen y se requería de 3cc para la inoculación de 1 $\mathrm{cc}$ por placa, para lo cual se agregó $2 \mathrm{cc}$ de solución salina al 0,9\% teniendo como resultado una proporción 3 en 1 (3:1) tomado en cuenta para el cálculo posterior de unidades de formación de colonias por placa.

Se realizó las inoculaciones en las Placas Petrifilm de 3M: Aerobios Totales, E. Coli y Coliformes, Hongos y Levaduras; en cada una se colocó 1cc de muestra dispensado con el mismo tubo del hisopo Quick Swab el mismo que tiene la propiedad de doblarse y posee señalización para cada cc de muestra. Se levantó el film superior de la placa y se colocó 1cc de muestra en el centro de cada placa petrifilm, se bajó el film superior dejándolo caer y se esperó un minuto que solidifique el gel del medio de cultivo.

Se colocó las placas apiladas en grupos de 20 como permitía el fabricante y se colocó en las incubadoras a $35^{\circ} \mathrm{C}$ las placas de Aerobios totales, E. coli y Coliformes por 2 días; y a $25^{\circ} \mathrm{C}$ las placas de Hongos y Levaduras por 5 días.

Después de los tiempos estimados se realizó el conteo de las ufc de cada placa de acuerdo a las guías de interpretación especificadas por el fabricante de Placas Petrifilm. 
Vol. 3, núm. 1, enero, 2017, pp. 50-72

Grado de contaminación en los teléfonos celulares de docentes y estudiantes que realizan actividades en la clínica LAS CIENCIAS odontológica

Para el procesamiento de datos se empleó el paquete estadístico SPSS en su versión 23 en español, con el cual se elaboraron las tablas de contingencia, gráficas estadísticas y principalmente la estimación de la significancia en las pruebas de ANOVA para el análisis cuantitativo y Chi cuadrado para el análisis cualitativo.

\section{Resultados.}

La información recabada de la encuesta fue la siguiente:

De la población muestreada, el 90\% es decir la mayoría, afirmó que siempre lleva su teléfono celular a clínicas durante su horario de atención.

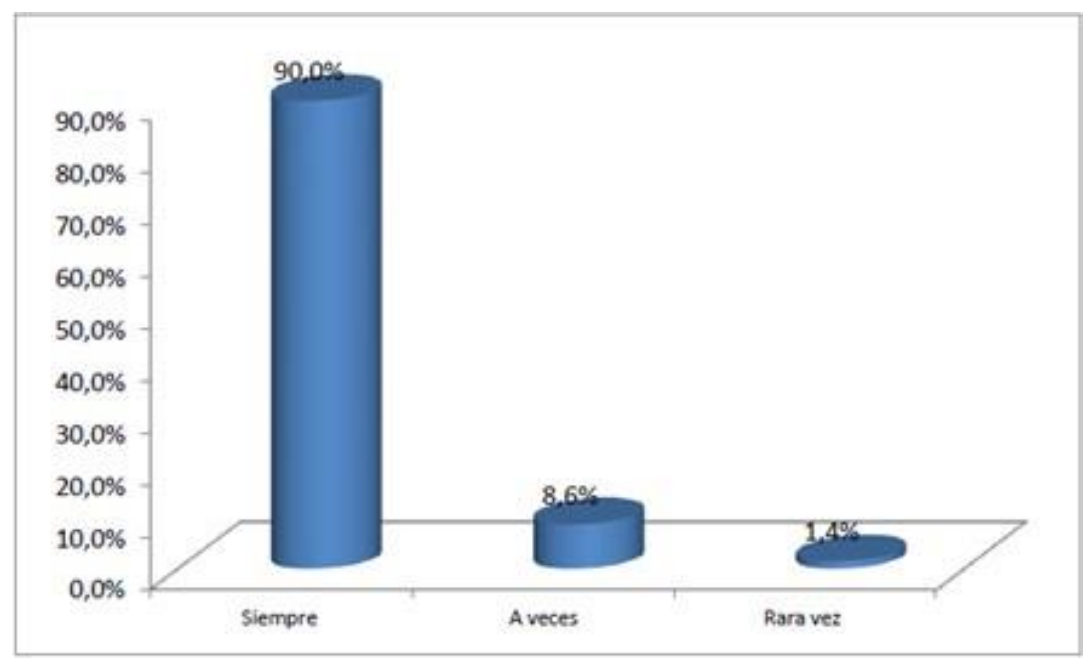

Gráfico $N^{\circ}$ 1.- Resultados de la pregunta: ¿Con qué frecuencia lleva su teléfono celular a clínicas durante su horario de atención? 
Vol. 3, núm. 1, enero, 2017, pp. 50-72

Grado de contaminación en los teléfonos celulares de docentes y estudiantes que realizan actividades en la clínica odontológica

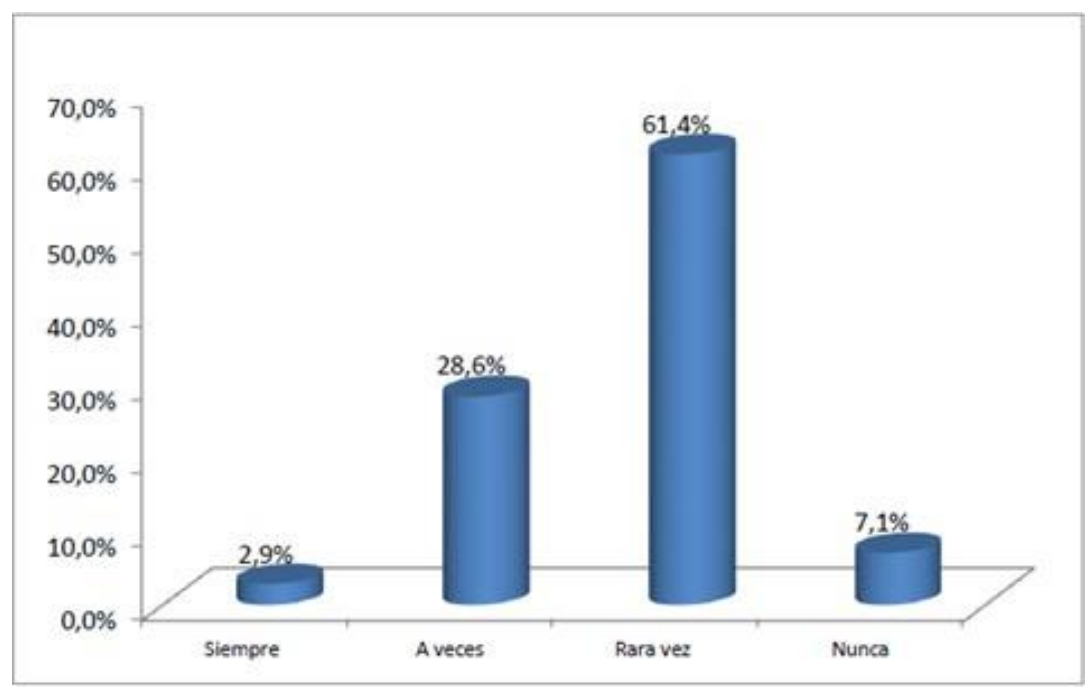

Gráfico $N^{\circ}$ 2.- Resultados de la pregunta: ¿Durante la atención al paciente con qué frecuencia interrumpe la atención para utilizar su teléfono celular?

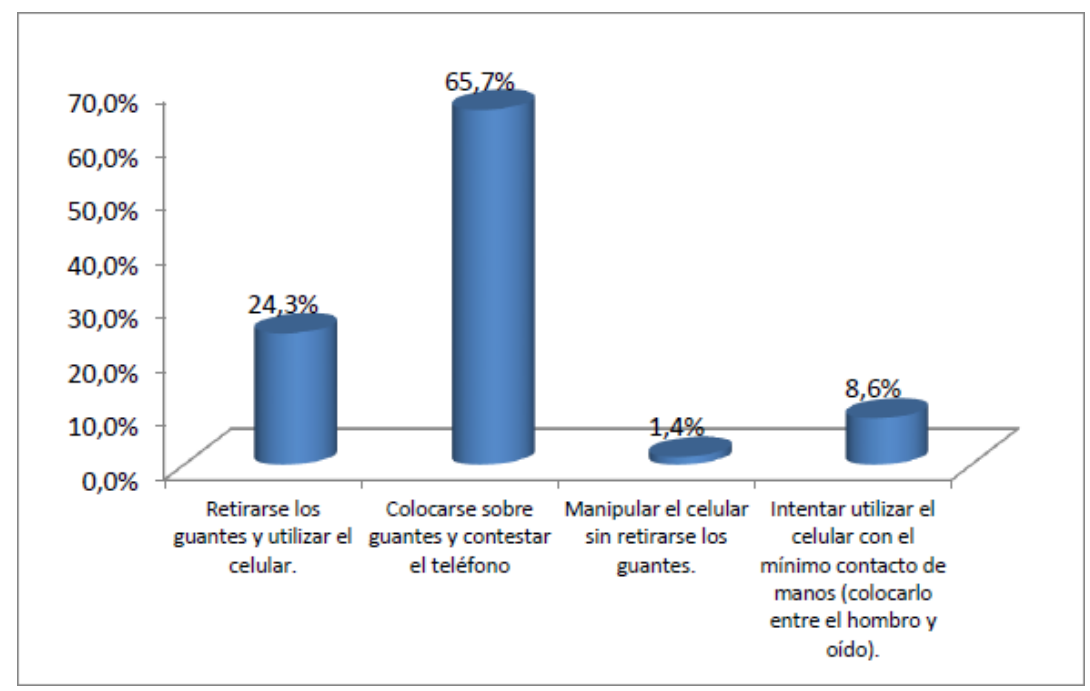

Gráfico $N^{\circ}$ 3.- Resultados de la pregunta: Acción a seguir en caso de que se encuentre atendiendo un paciente y requiera utilizar su teléfono celular. 
Vol. 3, núm. 1, enero, 2017, pp. 50-72

Grado de contaminación en los teléfonos celulares de docentes y estudiantes que realizan actividades en la clínica odontológica

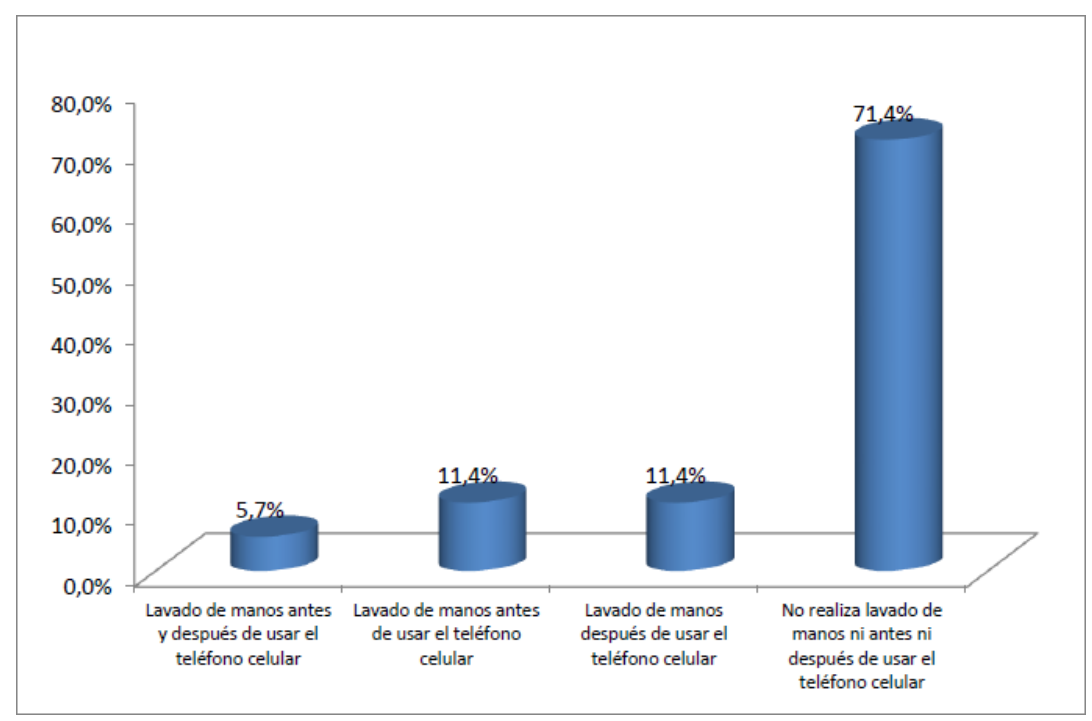

Gráfico $N^{\circ}$ 4.- Resultados de la pregunta: En caso de necesitar atender su teléfono celular durante la atención a un paciente, usted realiza

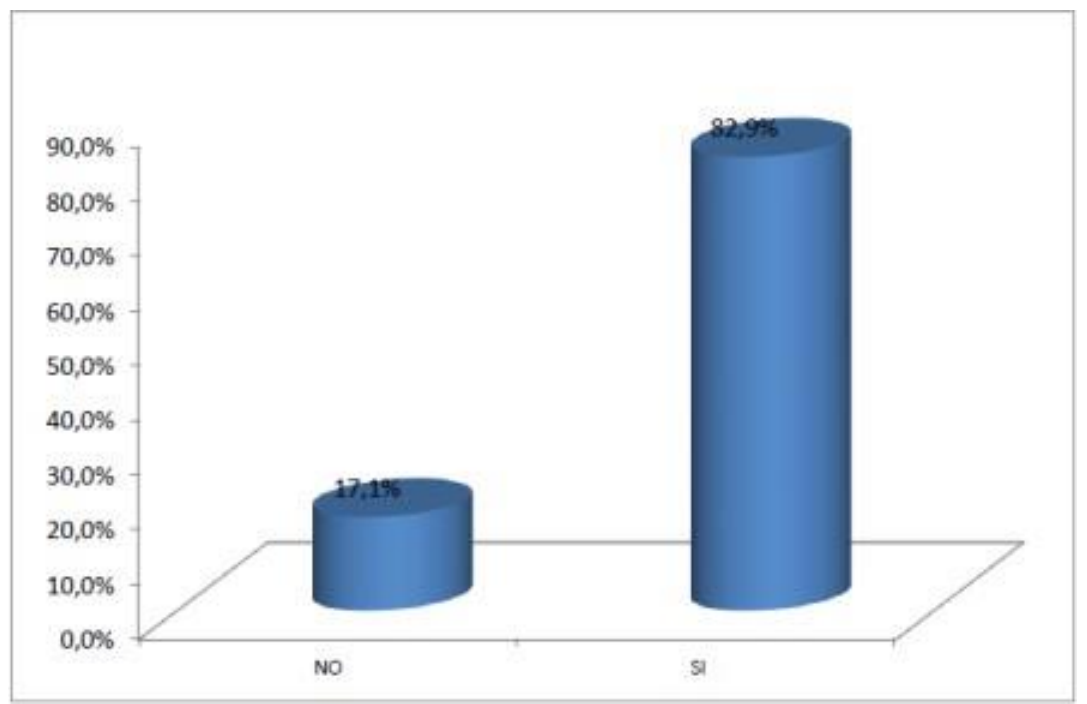

Gráfico $N^{\circ}$ 5.- Resultados de la pregunta: Una vez concluida la atención a un paciente, y antes de utilizar su teléfono celular, usted, realiza un lavado de manos. 
Vol. 3, núm. 1, enero, 2017, pp. 50-72

Grado de contaminación en los teléfonos celulares de docentes y estudiantes que realizan actividades en la clínica odontológica

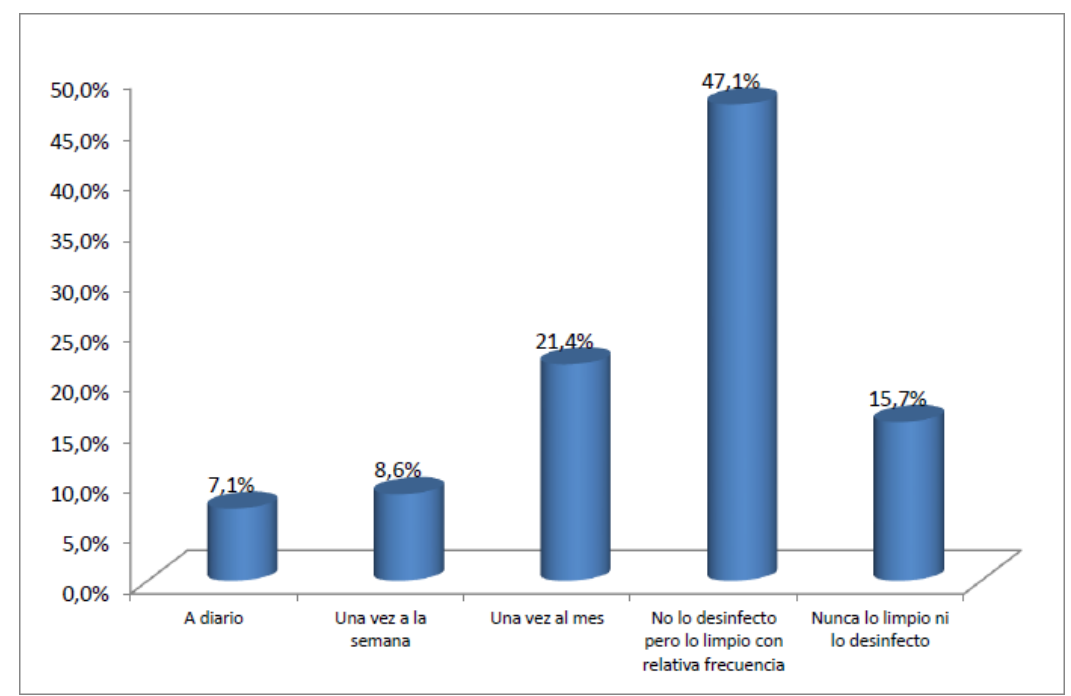

Gráfico $N^{\circ}$ 6.- Resultados de la pregunta: Con qué frecuencia desinfecta su teléfono celular.

En caso de que usted realice la desinfección de su teléfono celular, con qué lo hace.

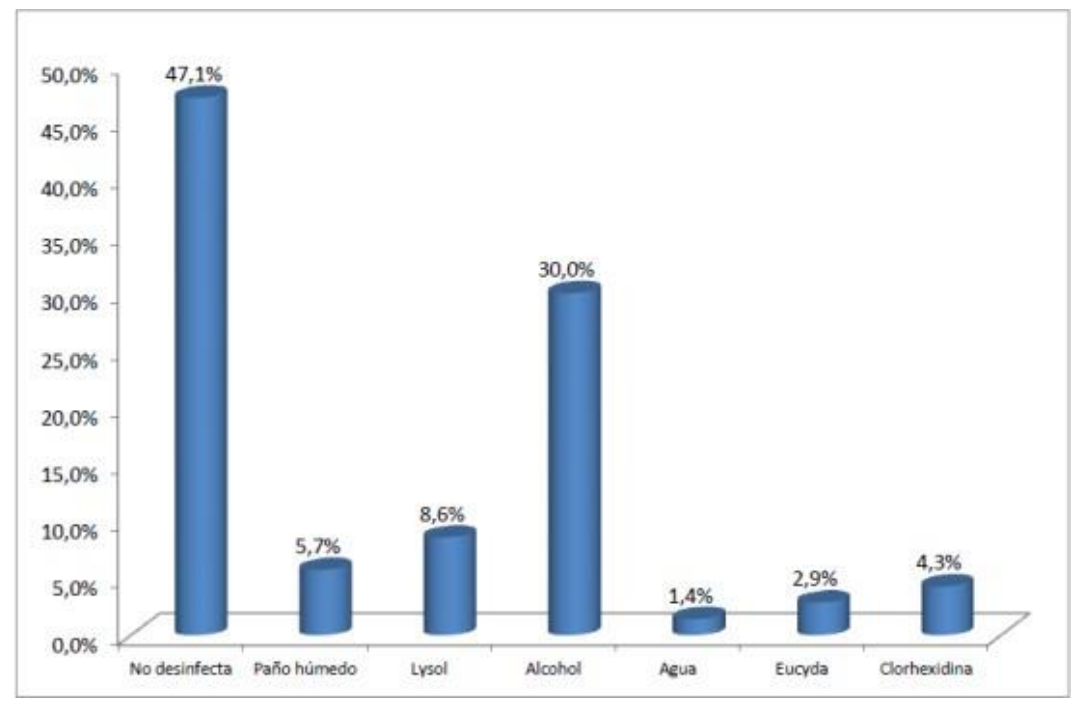

Gráfico $N^{\circ}$ 7.- Resultados de la pregunta: En caso de que usted realice la desinfección de su teléfono celular, con qué lo hace. 
Grado de contaminación en los teléfonos celulares de docentes y estudiantes que realizan actividades en la clínica odontológica

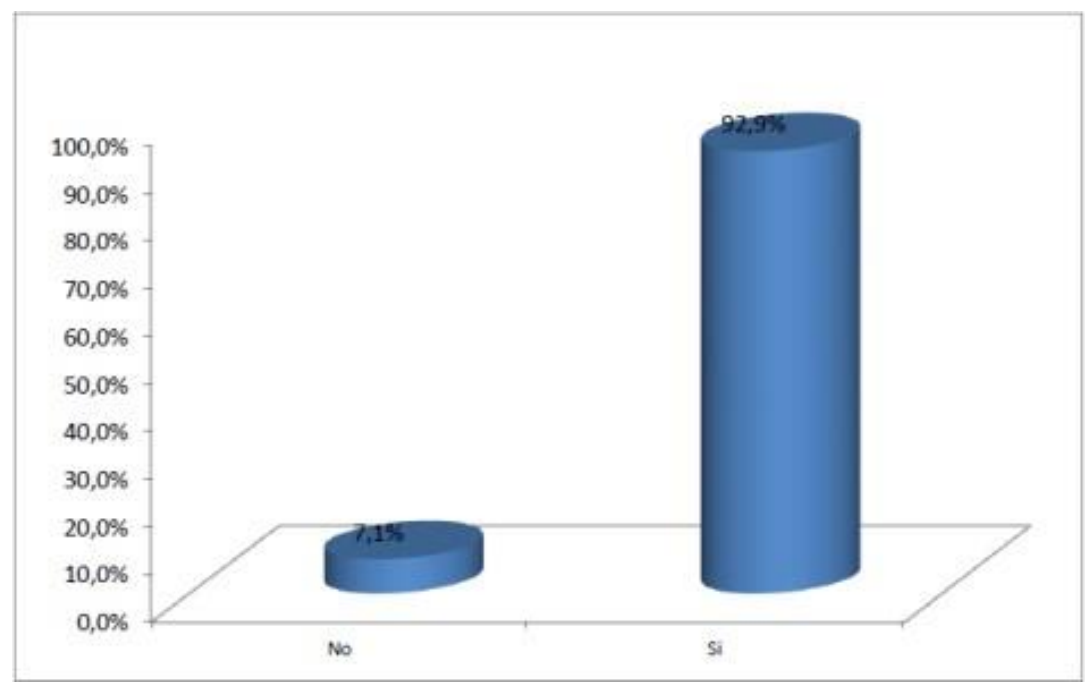

Gráfico $N^{\circ}$ 8.- Resultados de la pregunta: Considera que el celular constituye un medio de transmisión de infecciones cruzadas entre pacientes y el entorno.

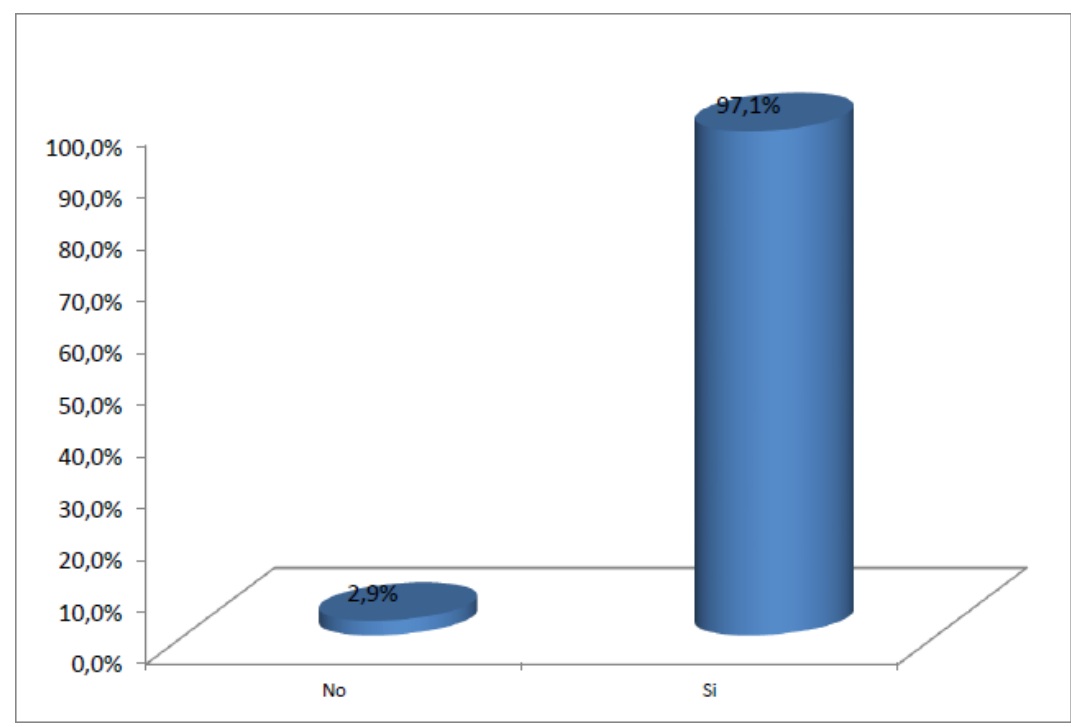

Gráfico $N^{\circ}$ 9.- Resultados de la pregunta: Considera que se deberían proponer normas básicas de bioseguridad para la utilización de los teléfonos celulares dentro del área clínica. 
Vol. 3, núm. 1, enero, 2017, pp. 50-72

Grado de contaminación en los teléfonos celulares de docentes y estudiantes que realizan actividades en la clínica LAS CIENCIAS odontológica

La mayoría de encuestados 62,9\% estima que la medida más adecuada a ser implementada como protocolo de bioseguridad relacionados con el uso de teléfonos celulares en la atención clínica, debería ser la de realizar la desinfección periódica del celular; antes y después de la atención de pacientes.

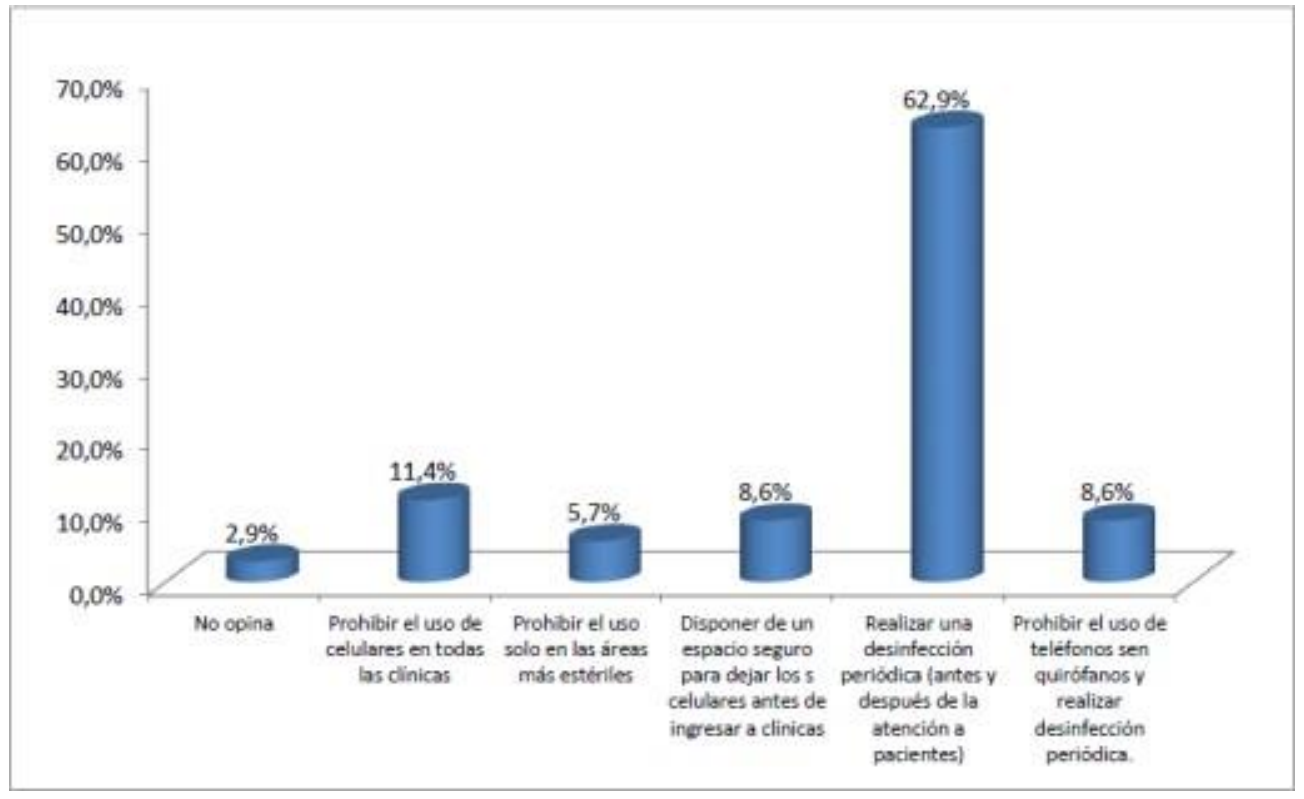

Gráfico $N^{\circ}$ 10.- Resultados de la pregunta: ¿Qué tipo de medida considera más adecuada para implementar protocolos de bioseguridad relacionados con el uso de teléfonos celulares en la atención clínica? 
Vol. 3, núm. 1, enero, 2017, pp. 50-72

Grado de contaminación en los teléfonos celulares de docentes y estudiantes que realizan actividades en la clínica odontológica

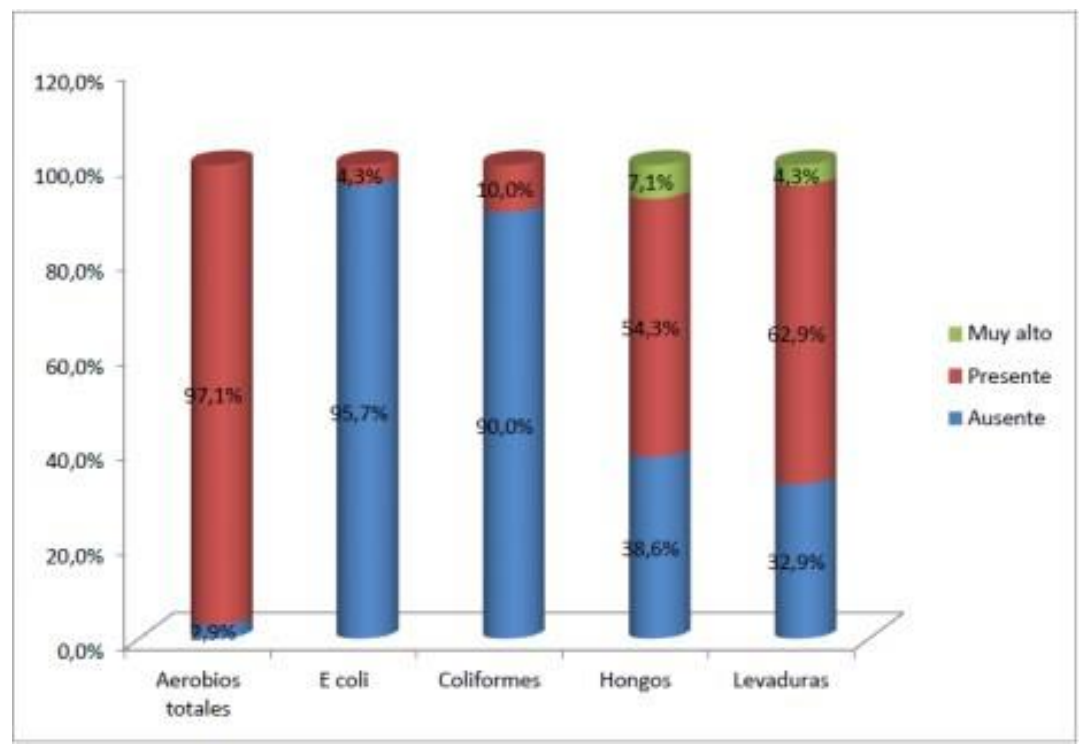

Gráfico $N^{\circ}$ 11.- Porcentajes de la presencia y ausencia de microorganismos antes de la desinfección con alcohol isopropílico.

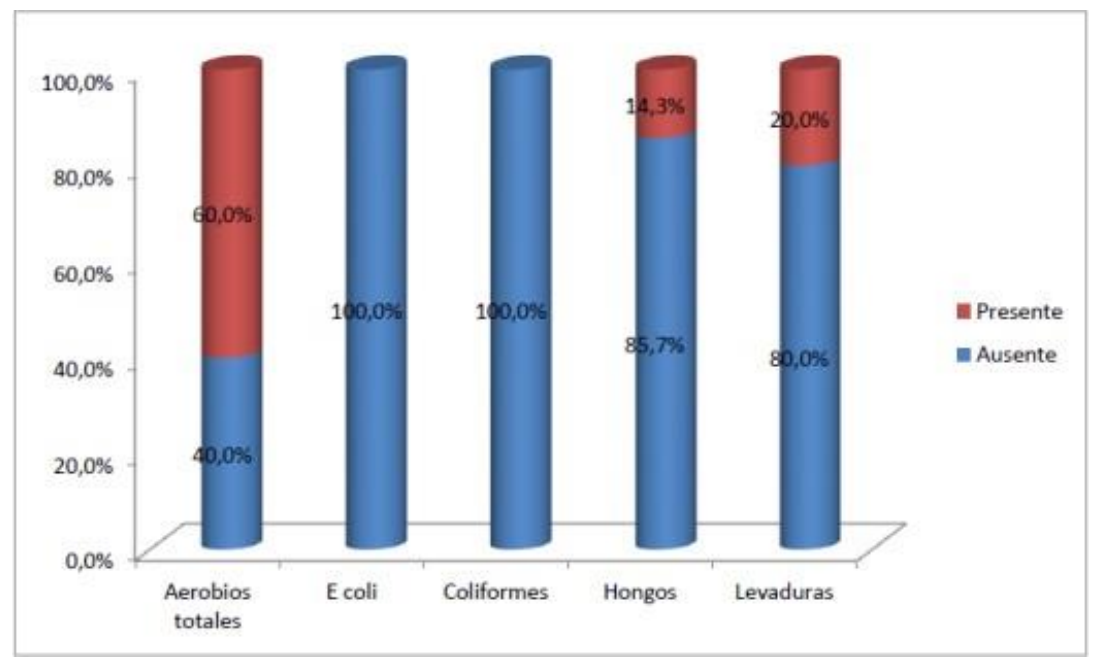

Gráfico $N^{\circ}$ 12.- Porcentajes de la presencia y ausencia de microorganismos después de la desinfección con alcohol isopropílico. 
Dom. Cien., ISSN: 2477-8818

Vol. 3, núm. 1, enero, 2017, pp. 50-72

Grado de contaminación en los teléfonos celulares de docentes y estudiantes que realizan actividades en la clínica odontológica

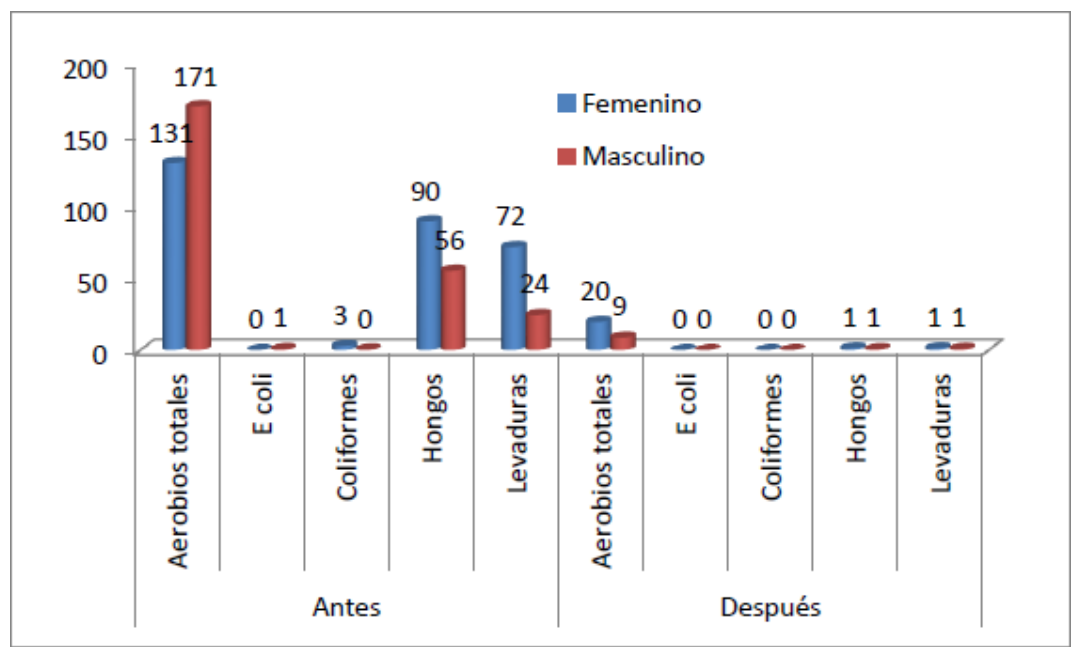

Gráfico $N^{\circ} 13 .-$ UFC por tipo de microorganismo antes y después por género.

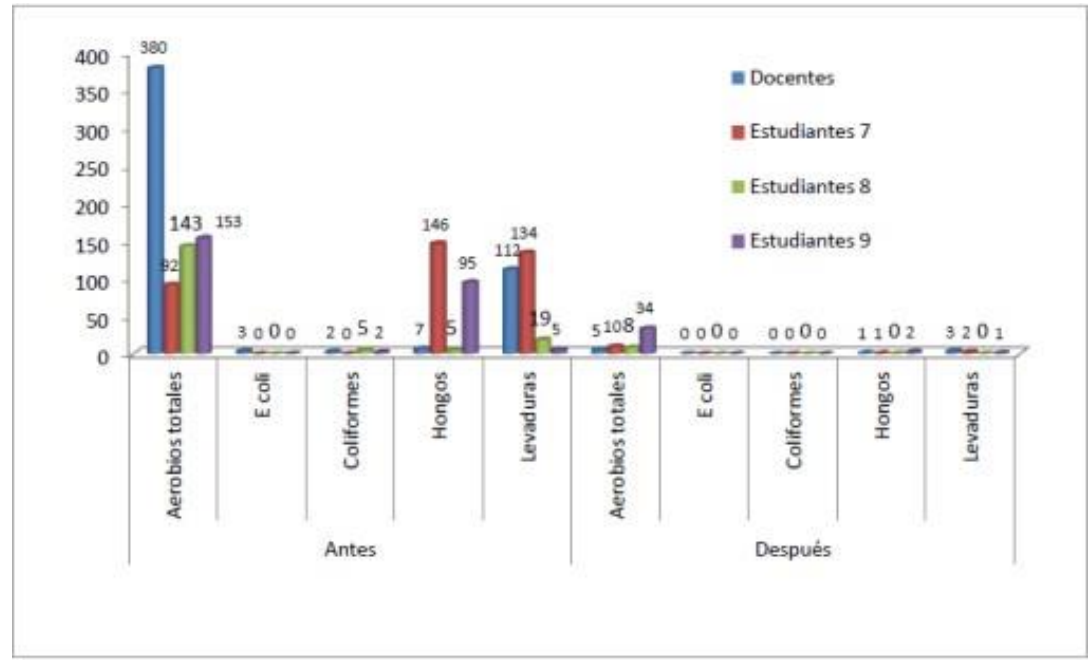

Gráfico $N^{\circ}$ 14.- UFC por tipo de microorganismo antes y después por grupo. 
Dom. Cien., ISSN: 2477-8818

Vol. 3, núm. 1, enero, 2017, pp. 50-72

Grado de contaminación en los teléfonos celulares de docentes y estudiantes que realizan actividades en la clínica odontológica

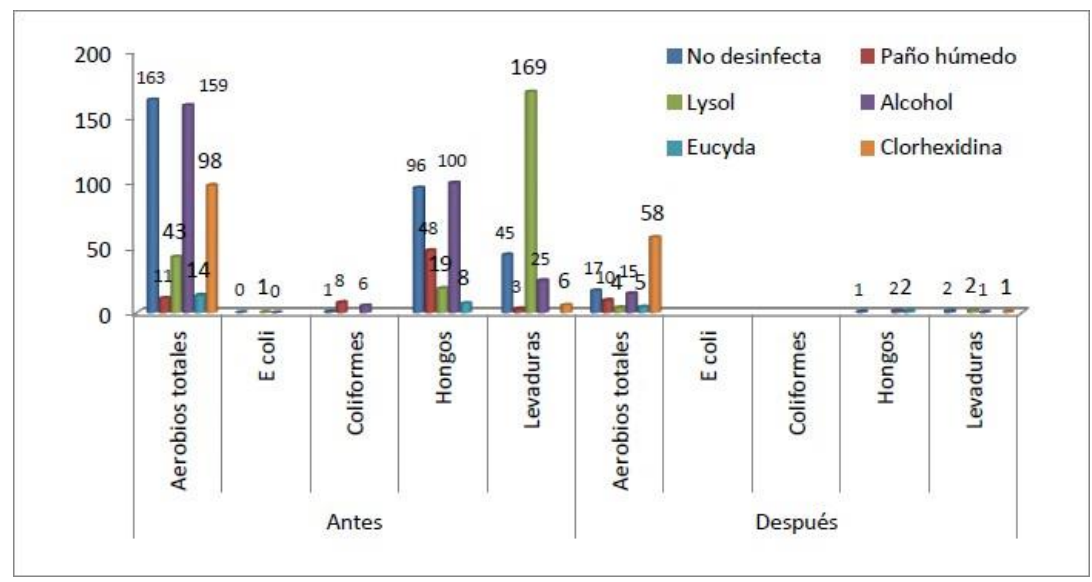

\section{Gráfico $N^{\circ} 15 .-$ UFC por tipo de microorganismo antes y después por hábito de desinfección.}

La cantidad de bacterias aerobias totales, coliformes, hongos y levaduras mostró los siguientes resultados en la siguiente ( $\left.\operatorname{tabla} n^{\circ} \mathbf{1}\right)$ la cual presenta el valor medio en UFC por tipo de microorganismo, así como su desviación estándar (DE) en las etapas pre y post desinfección. En ciertos casos el número de UFC fue muy alta para ser contabilizada por lo que se asumió un valor de 1000.

Los aerobios totales estuvieron en mayor cantidad que el resto de microorganismos.

\begin{tabular}{cccccc|ccccc} 
& \multicolumn{4}{c|}{ Antes } & \multicolumn{4}{c}{ Despues } \\
\cline { 2 - 9 } Estadístico & $\begin{array}{c}\text { Aerobios } \\
\text { totales }\end{array}$ & Ecoli Coliformes Hongos Levaduras & $\begin{array}{c}\text { Aerobios } \\
\text { Ecoli Coliformes Hongos Levaduras } \\
\text { totales }\end{array}$ \\
\hline Media & 143 & 0 & 2 & 80 & 58 & 17 & 0 & 0 & 1 & 1 \\
$\begin{array}{c}\text { Desviación } \\
\text { estándar (DE) }\end{array}$ & 229 & 2 & 10 & 258 & 209 & 49 & 0 & 0 & 4 & 3
\end{tabular}

Tabla $N^{\circ}$ 1.- UFC por tipo de microorganismo en las etapas pre y post desinfección 
La prueba de ANOVA determinó que existió una diferencia significativa en el número medio de UFC para la etapa pre y post desinfección, en todos los casos las significancia $(\mathrm{p}<0,05)$.

\section{Discusión.}

Un estudio en Venezuela en una clínica Odontológica en la que de 52 individuos entre profesionales y alumnos, el $81 \%$ indicaron en la encuesta que hacen uso de su teléfono celular dentro del área clínica; que la acción más frecuente al utilizar el teléfono celular en el área de trabajo es que el $33 \%$ no lo revisa sino esperan hasta terminar el trabajo. (3)

En comparación con el presente estudio, de acuerdo a la encuesta aplicada a 70 individuos dos el 90\% de ellos lleva siempre su teléfono celular a clínicas durante su horario de atención; que la acción más frecuente al utilizar el teléfono celular en el área de trabajo es que el 65,6\% se coloca sobre guantes y contesta el teléfono; además, la mayoría 71,4\%está consciente de que en caso de necesitar atender el teléfono celular durante la atención a un paciente no realiza lavado de manos ni antes ni después de usarlo.

Las causas probables pueden deberse a la falta de un reglamento y protocolos en cuanto a la utilización del teléfono celular dentro del área clínica; y ya que este dispositivo electrónico se ha vuelto indispensable en la actualidad debido a que brinda facilidades en la comunicación, información, tecnología, entretenimiento, y varias ventajas más que hacen que los docentes y estudiantes lo usen constantemente durante sus procedimientos clínicos y pasen por alto normas de bioseguridad con estos dispositivos, aumentando el riesgo de provocar infecciones cruzadas. 
En su estudio mostraron que de los 52 individuos encuestados, el $63 \%$ no efectúan ninguna vez limpieza a su teléfono móvil, el $4 \%$ lo hace una vez cada dos meses o más, el $8 \%$ lo realiza una vez al mes, $13 \%$ lo hace una a tres veces por semana, un $4 \%$ una vez al día y el $8 \%$ lo hace dos o más veces. (3)

En el presente estudio de los 70 encuestados, el 47,1\% indicaron que no lo desinfectan pero lo limpian con relativa frecuencia, mientras que el $15,7 \%$ no lo limpian ni lo desinfectan nunca, el $21,4 \%$ lo realizan una vez al mes, el $8,6 \%$ una vez a la semana y solo el 7,1\% lo hacen a diario.

El porcentaje de personas que realizan desinfección o limpieza de su teléfono móvil es muy bajo en ambos estudios, lo que puede ser debido a la falta de conocimiento de formas apropiadas para realizar dichos procesos, así como de los riesgos que este posee de transmitir enfermedades infecciosas por los patógenos que puede albergar. Porter, Caroline; 2012, menciona en su artículo que los productos de limpieza que se comercializa para teléfonos móviles pueden dañar el revestimiento de la pantalla o no eliminar 100\% los gérmenes y mencionó que “Apple explícitamente prohíbe el uso de "productos de limpieza de ventanas, aerosoles, disolventes, alcohol, amoníaco ni abrasivos" para limpiar el iPhone o cualquier otro producto de la firma. El asesoramiento de BlackBerry es similar. Su manual indica: "No use limpiadores líquidos en forma de aerosol ni disolventes en el dispositivo BlackBerry". (4)

Shahaby, A.F, et al. 2012, llevaron a cabo un estudio en la Faculta de Medicina de la Universidad de Taif en un total de 101 teléfonos celulares de estudiantes, médicos y enfermeras; en el cual el 77,2\% de los teléfonos celulares presentó contaminación bacteriana con diferentes tipos de 
Dom. Cien., ISSN: $2477-8818$

Vol. 3, núm. 1, enero, 2017, pp. 50-72

Grado de contaminación en los teléfonos celulares de docentes y estudiantes que realizan actividades en la clínica odontológica

bacterias; mientras que no se registró crecimiento en $22,8 \%$ de teléfonos celulares y a cerca del 21,8\% de los teléfonos móviles estaban contaminados con E. Coli. (5)

Comparando con el presente estudio se demostró que de 70 teléfonos celulares el 97,1\% de estos presentaron contaminación bacteriana y el 2,9\% ningún crecimiento; el 4,3\% de los teléfonos celulares presentaron E. Coli y Coliformes un $10 \%$.

Estos datos sugieren que los teléfonos móviles presentan alta contaminación bacteriana debido a la proximidad a partes sensibles del cuerpo como: cara, orejas, labios y manos de sus dueños; el tipo de profesión de sus usuarios como es la Odontología produce un índice mayor de contaminación puesto que el trabajo habitual conlleva contacto físico con sangre y saliva y además la producción de aerosoles y salpicaduras durante muchos procedimientos dentales representan una fuente potencial de transmisión de diversas enfermedades; y además el hecho de que los docentes y estudiantes no practican la higiene correcta y con frecuencia a sus teléfonos celulares.

Usha A, et al. 2009; encontraron la eficacia de descontaminación del alcohol isopropílico al $70 \%$ sobre los teléfonos celulares del personal de salud de un hospital de la India que fue efectivo al 98\%, ya que solo 5 teléfonos mostraron crecimiento post desinfección en un total de 160 teléfonos celulares; (6) en otro estudio demostraron que la eficacia de descontaminación fue de 71,3\% ya que de 101 teléfonos solo 29 presentaron crecimiento post desinfección. (5)

Mientras que en el presente estudio al realizar el análisis en la etapa posterior a la desinfección con alcohol isopropílico al 70\% se determinó que el 60\% de las muestras persistían bacterias aerobias totales, en el 20\% levaduras y en el 14,3\% hongos, no se registró contaminación ni de E. Coli ni de coliformes, lo que determina al alcohol isopropílico al $70 \%$ efectivo en un $40 \%$ 

odontológica

para bacterias aerobias totales; $100 \%$ para E. Coli y Coliformes; $85,7 \%$ para hongos y $80 \%$ para levaduras pudiéndolo usar como un agente de desinfección rápido.

Esto puede deberse a que existen microorganismos resistentes a este tipo de agente de desinfección y logran sobrevivir en ambientes más hostiles; por lo que resulta indispensable encontrar una alternativa de desinfección efectiva en eliminar la carga microbiana de los teléfonos y que sea adecuado para no dañar el sistema del aparato.

De esta manera la hipótesis del presente estudio queda comprobada debido a que, se encontró contaminación microbiana en la mayoría de los teléfonos celulares de una muestra de docentes y estudiantes que realizan procedimientos odontológicos en la Clínica Integral de la Facultad de Odontología de la Universidad Central del Ecuador; produciendo un mayor riesgo de transmisión de enfermedades infecciosas entre los estudiantes, docentes y pacientes e incluso llegar hasta sus familiares.

\section{Conclusiones.}

Se determinó que la mayor parte de teléfonos celulares de una muestra de docentes y estudiantes tienen un grado de contaminación elevado puesto que el 97,1\% presentaron crecimiento microbiano por lo que este si podría actuar como un fómite en la producción de infecciones cruzadas.

Los hábitos y actitudes de los encuestados en cuanto a la manipulación del teléfono celular durante la atención clínica es inapropiada puesto que el 71,4\% de los encuestados no realiza lavado 
de manos ni antes ni después de usarlo; además que el 90\% de encuestados tiene el hábito de llevar su teléfono celular a clínicas durante su horario de atención.

La periodicidad de desinfección de los teléfonos celulares es escasa puesto que la mayoría $62,8 \%$ no desinfectan su celular; el 21,4\% desinfecta su celular una vez al mes; el $8,6 \%$ lo desinfecta una vez a la semana y apenas el 7,1\% de los encuestados lo hacen a diario.

Se determinó que el microorganismo de mayor presencia se relacionó con aerobios totales 97,1\%; seguidos por hongos 62,9\% y levaduras 54,3\%; Coliformes en un 10\%; E. Coli en el 4,3\% de los teléfonos.

La prueba de ANOVA determinó que existió una diferencia significativa en el número medio de UFC para la etapa pre y post desinfección, cuya es significancia $p<0,05$; lo que comprueba la eficacia del alcohol isopropílico como desinfectante óptimo para disminuir la carga microbiana del teléfono celular. 


\section{Bibliografía.}

1. Goldblatt J, Krief I, Klonsky T, Haller D, Milloul V, Sixsmith D, et al. Use of cellular telephones and transmission of pathogens by medical staff in New York and Israel. Infect Control Hosp Epidemiol. 2007 apr; 28(4): p. 500-503.

2. Campos-Bedolla P, Bazán B, Sanmartí N, Torres D, Mingo B, Fernández M, et al. Biología I México: Limusa; 2003.

3. Muñoz-Escobedo J, Varela-Castillo L, Chávez-Romero P, Becerra-Sánchez A, Moreno-García M. Bacterias patógenas aisladas de teléfonos celulares del personal y alumnos de la Clínica Multidisciplinaria (CLIMUZAC) de la unidad Académica de Odontología de la UAZ. Archivos Venezolanos de Farmacología y Terapéutica. 2012 jun; 31(2): p. 23-31.

4. Porte C. Calling All Germs. The Wall Street Journal \& Breaking News. 2012 oct; 25(3).

5. Shahaby A, Awad N, Tarras E, Bahobial A. Mobile phone as potential reservoirs of bacterial pathogens. African Journal of Biotechnology. 2012 nov; 11(92): p. 15896-15904.

6. Usha A, Pushpa D, Chadha A, Malhotra S. Cellphones A Modern Stayhouse For Bacterial Pathogens. JK SCIENCE. 2009 sep; 11(3): p. 127-129. 
Anexo.

\section{INDICACIONES DE USO DEL TELÉFONO CELULAR EN LAS CLÍNICAS DE LA FACULTAD DE ODONTOLOGÍA DE LA UNIVERSIDAD CENTRAL DEL ECUADOR}
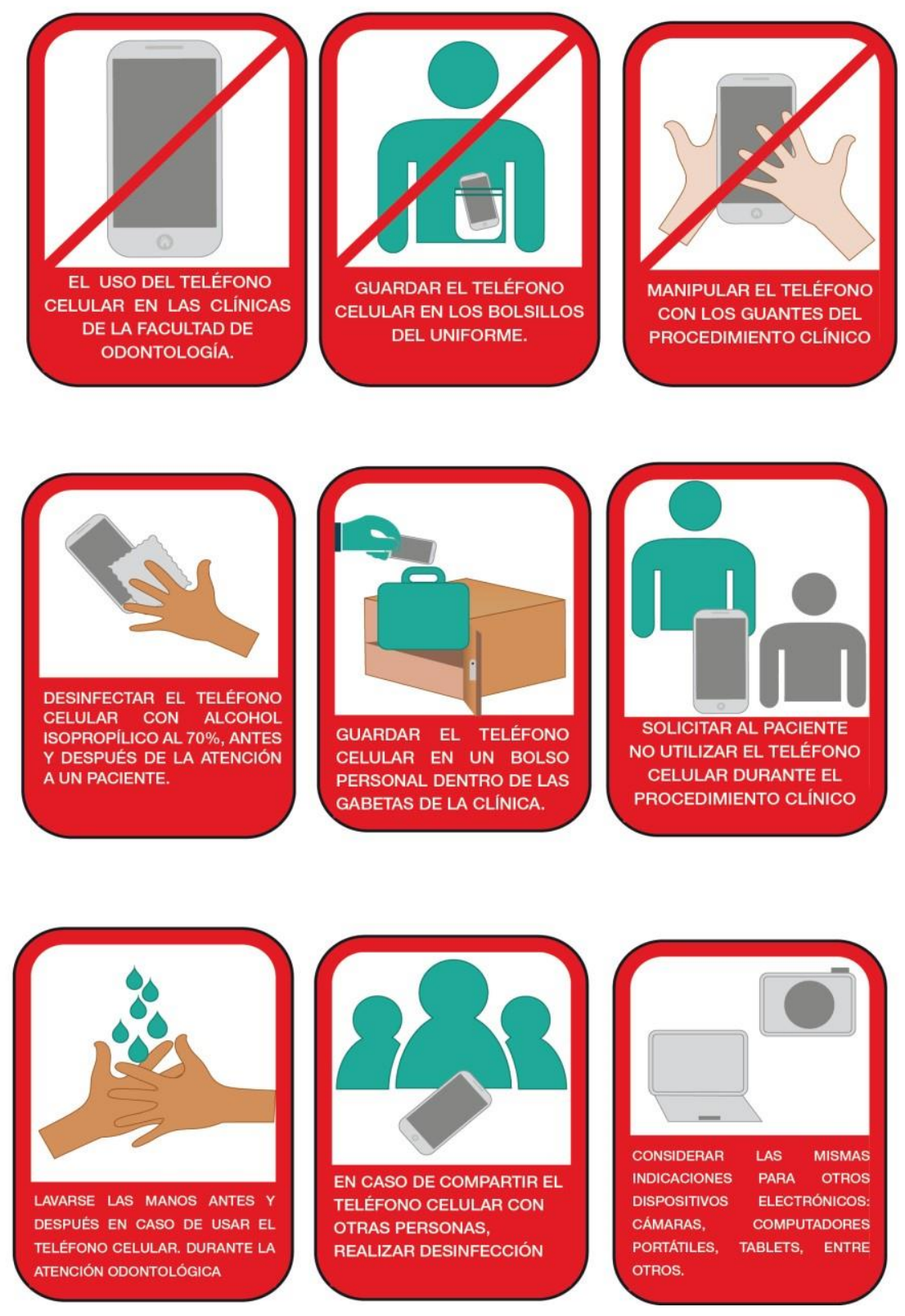